\title{
Programming Effect of the Parental Obesity on the Skeletal System of Offspring at Weaning Day
}

\author{
Radoslaw Piotr Radzki ${ }^{1, *(\mathbb{C})}$, Marek Bienko ${ }^{1, *(\mathbb{D})}$, Dariusz Wolski ${ }^{1}$, Monika Ostapiuk ${ }^{2}{ }^{(D}$, Pawel Polak ${ }^{3}$, \\ Malgorzata Manastyrska ${ }^{1}$, Aleksandra Kimicka ${ }^{1}$ and Joanna Wolska ${ }^{4}$
}

1 Department of Animal Physiology, Faculty of Veterinary Medicine, University of Life Sciences in Lublin, Akademicka 12, 20-033 Lublin, Poland; darek.wolski@o2.pl (D.W.); manastyrska.m@gmail.com (M.M.); aleksandra.kimicka@gmail.com (A.K.)

2 Department of Materials Engineering, Lublin University of Technology, Nadbystrzycka 36, 20-618 Lublin, Poland; m.ostapiuk@pollub.pl

3 St Johns' Oncology Center in Lublin (COZL) Trauma, Orthopaedic Surgery Department, ul. Jaczewskiego 7, 20-090 Lublin, Poland; ppolak.ort@gmail.com

4 Department of Oncology, Chair of Oncology and Environmental Health, Faculty of Health Sciences, Medical University of Lublin, 20-090 Lublin, Poland; wolska.joanna@o2.pl

* Correspondence: radoslaw.radzki@up.lublin.pl (R.P.R.); marek.bienko@up.lublin.pl (M.B.); Tel.: +48-81-445-60-69 (R.P.R.); +48-81-445-69-30 (M.B.)

check for updates

Citation: Radzki, R.P.; Bienko, M.; Wolski, D.; Ostapiuk, M.; Polak, P.; Manastyrska, M.; Kimicka, A.; Wolska, J. Programming Effect of the Parental Obesity on the Skeletal System of Offspring at Weaning Day. Animals 2021, 11, 424. https://doi. org/10.3390/ani11020424

Academic Editor: Brian D. Nielsen

Received: 18 December 2020

Accepted: 1 February 2021

Published: 6 February 2021

Publisher's Note: MDPI stays neutral with regard to jurisdictional claims in published maps and institutional affiliations.

Copyright: (c) 2021 by the authors. Licensee MDPI, Basel, Switzerland. This article is an open access article distributed under the terms and conditions of the Creative Commons Attribution (CC BY) license (https:// creativecommons.org/licenses/by/ $4.0 /)$.
Simple Summary: Overweight and obesity can cause many diseases, and several studies indicate a close relationship between the obesity of parents and the health of their offspring. Our aim was to investigate whether there is a programming influence of parental obesity on the skeletal system in weaned female and male offspring rats. In undertaking this, analysis of bone material was carried out using isolated tibia, and densitometry (DXA), peripheral (pQCT) and micro $(\mu C T)$ computed tomography were performed. Mechanical tests and blood serum biochemistry were also carried out. Our work showed a significant programming influence of parental obesity on neonatal skeletal development. The tibiae isolated from offspring originating from obese parents were characterized by more intense mineralization and higher fracture resistance. However, numerous studies demonstrate the destructive effect of obesity on the skeletal system. Our research and the available literature suggest the existence of a "fat threshold", the exceeding of which changes of the osteotropic effect of adipose tissue to become unfavorable. Therefore, there is a need for further research to determine the time-dependent metabolic relationship between adipose tissue and bone in both animals and humans.

Abstract: Our study aimed to verify the hypothesis of the existence of a programming effect of parental obesity on the growth, development and mineralization of the skeletal system in female and male rat offspring on the day of weaning. The study began with the induction of obesity in female and male rats of the parental generation, using a high-energy diet (group F). Females and males of the control group received the standard diet (group S). After 90 days of dietary-induced obesity, the diet in group F was changed into the standard. Rats from groups F and S were mated to obtain offspring which stayed with their mothers until 21 days of age. Tibia was tested using dual-energy X-ray absorptiometry (DXA), peripheral quantitative computed tomography (pQCT), micro-computed tomography $(\mu \mathrm{CT})$ and mechanical strength using the three-point bending test. Biochemical analysis of blood serum bone metabolism markers was performed. DXA analysis showed higher tibia bone mineral content (BMC) and area. pQCT measurements of cortical and trabecular tissue documented the increase of the volumetric bone mineral density and BMC of both bone compartments in offspring from the F group, while $\mu \mathrm{CT}$ of the trabecular tissue showed an increase in trabecular thickness and a decrease of its separation. Parental obesity, hence, exerts a programming influence on the development of the skeletal system of the offspring on the day of the weaning, which was reflected in the intensification of mineralization and increased bone strength. 
Keywords: prenatal programming; nutrition; bone metabolism and development; metabolic diseases; osteoporosis; bone mechanical examination; densitometry; pQCT; $\mu \mathrm{CT}$

\section{Introduction}

Nowadays, the problem of overweight and obesity has a global dimension and concerns both animals and humans. The main reasons for the development of this pathology are a diet rich in carbohydrates and fats, as well as low physical activity. Recently, much attention has been focused on the programming impact of parental obesity on the growth and development of offspring [1,2]. Some studies show that parental obesity may significantly contribute to the development of obesity of offspring, and as a consequence, of metabolic syndrome [3,4]. What is more, accordingly, obesity exerts a programming influence on the development of various organs [5].

Adipose tissue is the main energy supply in the body, but is also one of the largest endocrine organs, synthesizing and releasing several adipokines that affect the entire body, including bone [6]. The effect of adipose tissue is expressed not only through the direct effect of adipokinins on bone tissue, but also through their indirect, regulatory effect on the activity of other hormones important for metabolism, such as growth hormone $(\mathrm{GH})$ or $1.25(\mathrm{OH}) 2 \mathrm{D} 3[7,8]$. The osteotropic effect of adipose tissue is multidirectional and its nature has not been clearly defined. It is suggested that an increase in body weight is accompanied by stimulation of bone tissue formation by an increase in osteoblast proliferation and differentiation, reducing their apoptosis $[9,10]$. In contrast, excessive weight loss and reduced pressure on the pelvic limb bone, or its immobilization, intensify bone resorption [11]. There are reports indicating the different effect of excessive fat accumulation on bone tissue. Blum et al. [12] and Hsu et al. [13], for example, show that excessive fat mass is not a protective factor against metabolic diseases of bone tissue and even contributes to their development, which is low with low BMD and BMC.

Skeletal development during the perinatal period and in the subsequent stages of life before adolescence is important in achieving peak bone mass. It is estimated that about $30 \%$ of the peak bone mass depends on nutrition [14-16]. It should be emphasized that the composition of milk of obese mothers significantly differs from the composition of milk of mothers with normal body weight [17]. Such modification of nutrition in the perinatal period may have a significant influence on the development of bone tissue.

The study focused on determining whether and to what extent the established dietaryinduced obesity in parents before fertilization exerts a programming effect on the development of the female and male offspring's skeletal system on the weaning day. This research could significantly contribute to a better understanding of the relationship between obesity and bone tissue.

\section{Materials and Methods}

\subsection{Animal Procedures}

All the procedures were approved by the 2nd Local Ethics Committee in Lublin (Resolution $\mathrm{nr}$ 32/2015). The experimental population consisted of 32 female and 16 male Wistar rats (outbred herd from the Center of Experimental Medical in Bialystok Medical University-Cmdb:Wi, originating from Charles River) with initial body weight $230 \pm 20 \mathrm{~g}$. These rats were the parental generation. Throughout the experiment, the animals were exposed to artificial lighting, with the day/night ratio being $12 / 12 \mathrm{~h}$, except during the breeding period in which case it was $14 / 10 \mathrm{~h}$. Access to water and food was not restricted, and body weight was monitored once a week. The rats were randomly divided into two groups and fed with diets of different energy values. Group $S$ (females $n=16$, males $n=8$ ) received a standard diet with an energy value of $11.5 \mathrm{MJ} / \mathrm{kg}$, while group $\mathrm{F}$ (females $n=16$, males $n=8)$ received a high-energy diet valued at $17.6 \mathrm{MJ} / \mathrm{kg}(16 \%$ fat, $65 \%$ carbohydrates, $19 \%$ protein) (Agropol, Motycz, Poland). Both types of diets were followed for 90 days, 
i.e., the time necessary to induce obesity in groups of rats receiving $\operatorname{diet} \mathrm{F}[18,19]$ (Table 1) and then a high-energy diet in group $\mathrm{F}$ was changed into a standard diet. After 90 days the mean body weight of females in the S group was $383 \mathrm{~g} \pm 9$, and in the F group $484 \mathrm{~g} \pm 14$ $(p<0.0001)$, whereas in the males of the $S$ and $\mathrm{F}$ groups, the mean body weight was $632 \mathrm{~g} \pm 18$ and $766 \pm 18(p<0.0001)$, respectively.

Table 1. Standard $(S)$ and high-energy diets $(F)$ content.

\begin{tabular}{ccc}
\hline Ingredients & Standard Diet $(\boldsymbol{S})$ & High-Energy Diet $(\boldsymbol{F})$ \\
\hline Metabolic Energy & $11.50 \mathrm{MJ} / \mathrm{kg}$ & $17.6 \mathrm{MJ} / \mathrm{kg}$ \\
Crude protein & $16.00 \%$ & $20.0 \%$ \\
Crude fat min. & $2.80 \%$ & $21.0 \%$ \\
Crude ash max. & $7.00 \%$ & $5.58 \%$ \\
Crude fiber max. & $5.00 \%$ & $3.86 \%$ \\
Lysine & $0.80 \%$ & $1.2 \%$ \\
Methionine + Cysteine & $0.50 \%$ & $0.76 \%$ \\
Tryptophan & $0.190 \%$ & $0.27 \%$ \\
Calcium & $1.10 \%$ & $1.32 \%$ \\
Phosphorus & $0.70 \%$ & $0.54 \%$ \\
Natrium & $0.22 \%$ & $0.19 \%$ \\
Vitamin A & $8000 \mathrm{IU} / \mathrm{kg}$ & $8000 \mathrm{IU} / \mathrm{kg}$ \\
Vitamin D3 & $1000 \mathrm{IU} / \mathrm{kg}$ & $1000 \mathrm{IU} / \mathrm{kg}$ \\
Vitamin E & $50 \mathrm{mg} / \mathrm{kg}$ & $76.9 \mathrm{mg} / \mathrm{kg}$ \\
\hline
\end{tabular}

In the next step of the experiment female and male rats of the parental generation were placed in shared cages ( 2 females and 1 male in a cage) for 14 days (the time when fertilization should occur) to obtain offspring. The parental females were then separated and housed in individual cages. The average litter did not exceed 8-12 newborns. On the first day after birth, each litter was examined and initially sexed based on the method previously described [20], and the weight of all newborns was measured. Six offspring from the $S$ and the F parents were selected and left with their mother for the last step of the study (16 females $\times 6$ litters in each feeding group). The selection criterion was body weight, being close ( $\max \pm 0.5 \mathrm{~g}$ ) to the mean body weight of all females or males offspring in either the $S$ or the F group, respectively. On the seventh day after birth, the sex was confirmed and the body weight was measured again. Measurements were repeated at day 14 and 21. On the weaning day (21st day of life), 16 female offspring (group $S n=8$; group $\mathrm{F} n=8$ ) and 16 male offspring (group $\mathrm{S} n=8$; group $\mathrm{F} n=8$ ) were randomly selected and sacrificed. Immediately after sacrifice, subcutaneous, visceral, mesenteric fat tissues, as well as tibiae, were dissected and weighted. The length of the tibiae was established via pQCT analysis. The isolated tibia as well as blood serum were frozen $\left(-30^{\circ} \mathrm{C}\right)$ for further analysis.

\subsection{Dual X-ray Absorptiometry (DXA) Analysis of the Total Skeleton and Isolated Tibiae}

Lean mass (LM), fat mass (FM), areal total skeleton bone mineral density (Ts.BMD), total skeleton bone mineral content (Ts.BMC) and total skeleton area (Ts.Ar), as well as t.BMD; t.BMC and t.Ar for isolated right tibiae were examined via DXA analysis. The measurements were performed with the use of a Norland Excell Plus Densitometer (Fort Atkinson, WI, USA) equipped with Illuminatus Small Subject Scan v.4.5 software.

\subsection{Peripheral Quantitative Computed Tomography ( $p Q C T)$ Measurements of the Isolated Tibiae}

The right tibiae were measured with the use of the PQCT XCT Research SA Plus system and software version 6.2 C (Stratec Medizintechnik GmbH, Pforzheim, Germany). The bones were scanned perpendicularly to the long axis. The scan location was established using the scout view obtained after the initial pQCT system scan (pre-scan). The pre-scan was performed at a speed of $10 \mathrm{~mm} / \mathrm{s}$ and the CT scan was done at $4 \mathrm{~mm} / \mathrm{s}$. The cortical and trabecular bone tissue are separated by an appropriate superficial distribution of both 
bone compartments, and $55 \%$ of the outer surface of the bone is defined as the corticalsubcortical area and $45 \%$ of the internal core is defined as trabecular bone tissue. After the CT scan, the XCT Research algorithm based on the above settings (threshold, contour mode, peel mode, cortical mode) automatically calculated values for densitometric and architectural properties. Trabecular bone analyses were performed in contour mode 2 and a peel mode 20 (threshold $610 \mathrm{mg} / \mathrm{cm}^{3}$ ) in the proximal tibia metaphysis. The following parameters were obtained: total bone mineral content (Tot.BMC), total volumetric bone mineral density (Tot.vBMD), total surface bone area (Tot.Ar), trabecular bone surface area (Tb.Ar), trabecular bone mineral content (Tb.BMC) and trabecular volumetric bone mineral density (Tb.vBMD). In the analysis of cortical bone tissue in the mid-shaft of the tibia diaphysis, cortical mode 1 (threshold $710 \mathrm{mg} / \mathrm{cm}^{3}$ ) was used to obtain the following parameters: total and cortical volumetric bone mineral density (Tot.vBMD; Ct.vBMD), total and cortical bone mineral content (Tot.BMC; Ct.BMC) and cortical surface (Ct.Ar). Total area (Tot.Ar), periosteal (Peri. C) and endosteal (Endo C) circumferences and cortical thickness (Ct.Th) were measured using contour mode $1\left(710 \mathrm{mg} / \mathrm{cm}^{3}\right.$ threshold) to determine the outer edge of the bone, and peel mode $2\left(400 \mathrm{mg} / \mathrm{cm}^{3}\right.$ threshold) was used to separate the cortical and subcortical/medullary compartments. The Ct.Th, Endo.C and Peri.C measurements were based on a circular ring model where the spinal area was defined as the difference of total area and cortical area. Before measurements, a daily system calibration was performed using a hydroxyapatite standard, containing a quality control phantom (pQCT QA-Phantom).

\subsection{D Micro-Computed Tomography ( $\mu-C T$ ) Analysis of Trabecular Bone Tissue Morphometry}

The micro CT technique with the use of a Micro CT SkyScan 1174 (Bruker-SkyScan, Kontich, Belgium) was performed to examine the proximal part of the tibia. The micro CT apparatus was equipped with a VDS 1.3Mp FW camera (resolution of $1024 \times 1024$ ), a $0.5 \mathrm{~mm}$ aluminum filter, and a lamp of $50 \mathrm{kV}$ and $800 \mu \mathrm{A}$. All tibia scans were performed $1.5 \mathrm{~mm}$ from the proximal growth plate, with a rotation degree of $0.70^{\circ}$ and $2400 \mathrm{~ms}$ of time exposure. The mean number of frames was 4, image pixel size was $9.64 \mu \mathrm{m}$, and the average time of scanning was $1 \mathrm{~h}$ and $5 \mathrm{~min} 50 \mathrm{~s}$. With the use of NRecon 1.6.1.5 software (SkyScan n.v., Kontich, Belgium) the reconstructions of the tibia were performed. Analysis of the internal structure was generated by CT Analyser software ver. 1.15.4.0 (SkyScan n.v., Kontich, Belgium) which allowed the obtaining of three-dimensional reconstructions and 3D information by stacking measured slices on top of each other. The following parameters were measured: bone volume (BV), total volume (TV), bone volume density (BV/TV), bone surface (BS), object surface density (BS/TV), trabecular number (Tb.N), trabecular thickness ( $\mathrm{Tb} . \mathrm{Th}$ ), trabecular separation (Tb.Sp) and structure model index (SMI).

\subsection{Mechanical Properties}

The mechanical strength of bone tissue was determined by two methods. Tomographic analysis (pQCT) allowed for the establishment of the Strain/Strength Index (xSSI), enabling prediction of the mechanical strength of the bone. These measurements were carried out in the middle of the tibia's diaphysis (the measurement conditions described above). The real mechanical parameters of the isolated tibia were established based on the 3-point bending test, using a ZwickRoell Z010 (ZwickRoell GmbH \& Co. KG, Ulm, Germany) testing machine with a $1 \mathrm{kN}$ measuring head Xforce HP series. The analyzed bones were regarded as a tube model. Herein, the external and internal diameters were measured by pQCT. In doing so, the bone was placed on two holders, and the force was applied downward, perpendicularly to the long bone axis, at the midshaft of the bone column. The received data were analyzed by way of testXpert II 3.1 software assistance, and the ultimate strength (Fmax), work to ultimate strength (W/Fmax), and the Young modulus (Emod) were determined [21]. 


\subsection{Biochemical Analysis}

The serum concentration of osteocalcin (OC), also known as bone gammacarboxyglutamic acid-containing protein (BGLAP) (Immunodiagnostic Systems, Bolton, UK), C-terminal telopeptides of type I collagen (CTX-I) (Immunodiagnostic Systems, UK), 25 (OH)D3 (Immunodiagnostic Systems, UK) and bone-specific alkaline phosphatase (Immunodiagnostic Systems, UK) were assessed through enzyme-linked immunosorbent assay (ELISA), using the respective commercial kits. Ionized calcium and phosphorus were measured spectrophotometrically by way of commercial kits (Alphadiagnostic, Warsow, Poland) and a Mindray BS 120 apparatus (Mindray, Shenzhen, China).

\subsection{Statistical Analysis}

The results were presented as mean values \pm S.E.M $(n=8)$. To establish significant differences between control and experimental groups, the $t$-Student test was used. Differences were considered significant at $p<0.05$. Statistical analyses were performed using STATISTICA software v. 13.0 (Tibco Software Inc., Palo Alto, USA).

\section{Results}

\subsection{Body Weight, Body Composition, Tibia Length and Mass}

Body weight of newborns from parents fed the F diet, measured on the day of birth, was higher in both females (15\%) and males $(12 \%)$ compared to the mean birth weight of the rats from the parents fed the S. At weaning, these differences were $17 \%$ and $29 \%$, respectively (Table 2).

Table 2. The body weight (birthday and at weaning), masses of fat tissue depots, weight and length of tibia and parameters of body composition of female and male rats on the weaning day.

\begin{tabular}{|c|c|c|c|c|c|c|}
\hline \multirow{2}{*}{ Item } & \multicolumn{3}{|c|}{ Female } & \multicolumn{3}{|c|}{ Male } \\
\hline & $S$ & $F$ & $p$-Value & $S$ & $F$ & $p$-Value \\
\hline Body weight (birthday) (g) & $8.2 \pm 0.2$ & $9.5 \pm 0.3$ & 0.004 * & $8.5 \pm 0.2$ & $9.4 \pm 0.2$ & $0.002 *$ \\
\hline Body weight (weaning) (g) & $60.0 \pm 2.3$ & $70.4 \pm 1.4$ & $0.002 *$ & $66.0 \pm 0.9$ & $85.3 \pm 1.1$ & $<0.0001 *$ \\
\hline Subcutaneous fat (g) & $1.03 \pm 0.04$ & $1.25 \pm 0.09$ & $0.036^{*}$ & $1.08 \pm 0.08$ & $1.35 \pm 0.10$ & 0.046 * \\
\hline Visceral fat $(\mathrm{g})$ & $0.21 \pm 0.03$ & $0.54 \pm 0.07$ & $0.008 *$ & $0.21 \pm 0.03$ & $0.51 \pm 0.09$ & $0.003 *$ \\
\hline Mesenteric fat (g) & $0.38 \pm 0.03$ & $0.53 \pm 0.03$ & $0.007 *$ & $0.40 \pm 0.04$ & $0.51 \pm 0.02$ & $0.020 *$ \\
\hline Tibia mass (g) & $0.104 \pm 0.004$ & $0.107 \pm 0.003$ & 0.243 & $0.104 \pm 0.003$ & $0.109 \pm 0.003$ & 0.187 \\
\hline Tibia length (mm) & $23.2 \pm 0.4$ & $22.0 \pm 0.2$ & 0.301 & $22.9 \pm 0.5$ & $22.2 \pm 0.2$ & 0.277 \\
\hline Soft tissue mass (ST) (g) & $53.8 \pm 2.2$ & $57.9 \pm 2.4$ & 0.227 & $57.5 \pm 2.2$ & $61.2 \pm 2.2$ & 0.267 \\
\hline Fat tissue mass $(\mathrm{FM})(\mathrm{g})$ & $0.060 \pm 0.009$ & $0.552 \pm 0.079$ & $<0.0001^{*}$ & $0.072 \pm 0.009$ & $1.104 \pm 0.085$ & $<0.0001 *$ \\
\hline Lean mass $(\mathrm{LM})(\mathrm{g})$ & $57.4 \pm 1.8$ & $58.4 \pm 2.0$ & 0.730 & $61.4 \pm 1.4$ & $63.5 \pm 1.7$ & 0.345 \\
\hline
\end{tabular}

Results are the means \pm S.E.M. $(n=8)$. Statistically significant differences between $S$ and $F$ groups were established by the $t$-Student $(p<0.05)$ and marked by *

Fat Mass (FM) in both female and male offspring from group F was statistically significantly higher. Interestingly, LM and ST also tended to higher values in both sexes of offspring in group F. The weight and length of the tibia in both females and males in groups $\mathrm{F}$ and $\mathrm{S}$ were similar (Table 2).

\subsection{Mass of the Subcutaneous, Visceral and Mesenteric Fat Tissue}

The weight of the subcutaneous and mesenteric fat was significantly higher in female rats from group F (vs. S) by $21 \%$ and by $40 \%$, respectively. Surprisingly, we noted an almost 2.6 times increase of the weight of visceral fat in females from group F. In males, a significant increase in the depot of subcutaneous, mesenteric and visceral fat tissue by $25 \%$, $28 \%$ and about by $140 \%$ respectively, were also observed (Table 2 ). 


\subsection{DXA Measurements of the Whole Skeleton and the Isolated Tibia}

There were no significant differences in the total skeleton Ts.BMD values between groups $\mathrm{F}$ and $\mathrm{S}$. Diet $\mathrm{F}$ used in the parents, however, significantly increased the Ts.BMC (by 30\% in both sexes) and the Ts.Ar in the female and male offspring (by 34\% and 33\% respectively). The tibia of both sexes of offspring from parents fed the F diet, showed a statistically significant increase in t.BMC ( $23 \%$ and $27 \%$, respectively) and t.Ar ( $16 \%$ and $20 \%$, respectively) with similar values of t.BMD (Figure 1 ).

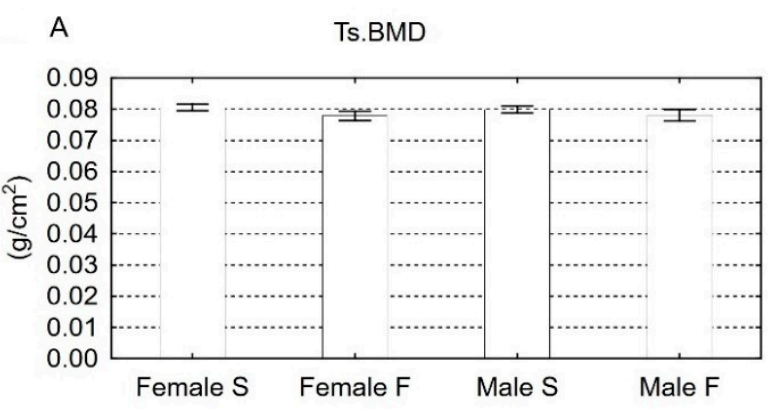

Ts.BMC

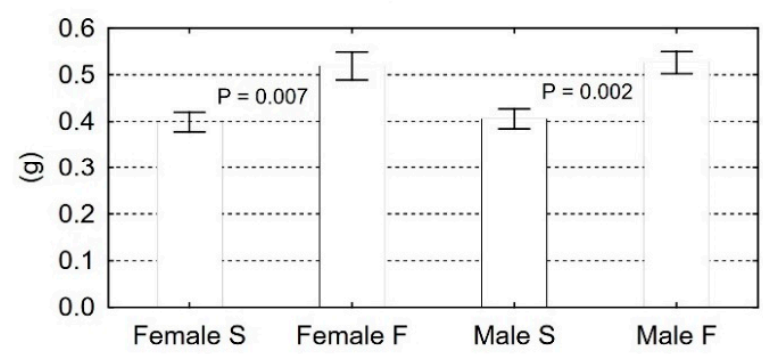

Ts.Ar

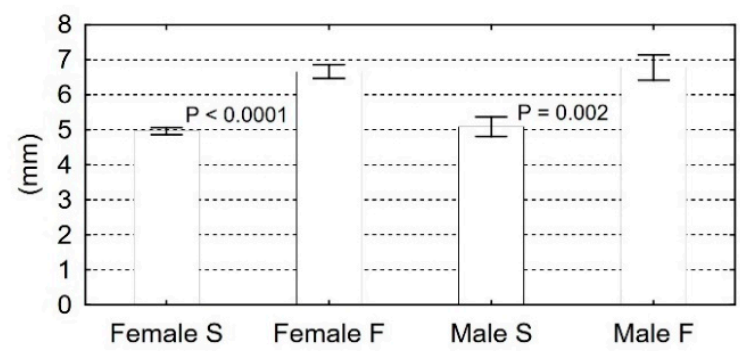

B $\quad$ t.BMD

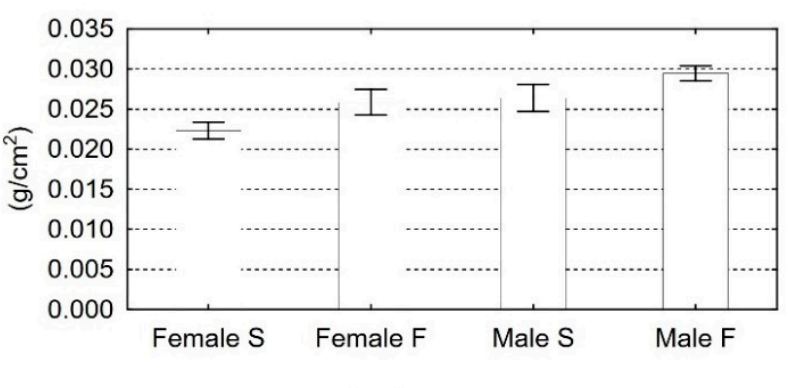

t.BMC

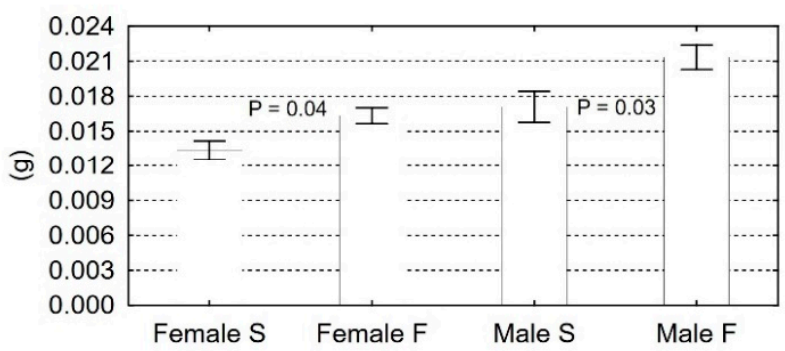

t.Ar

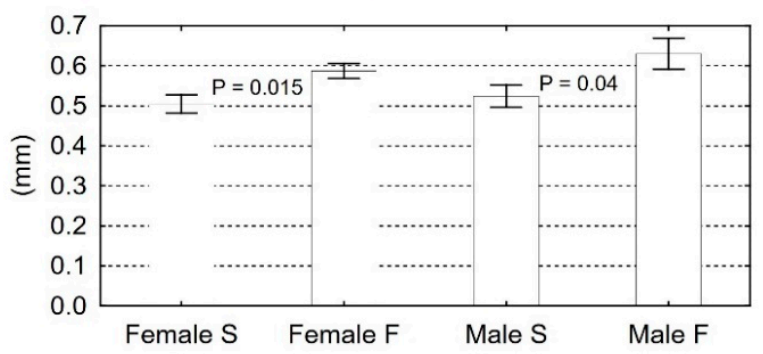

Figure 1. DXA analysis of total skeleton (A) and isolated tibia (B) of female and male rats on the weaning day. Results are the means \pm S.E.M. $(n=8)$. Statistically significant differences between $\mathrm{S}$ and $\mathrm{F}$ groups were established by the $t$-Student $(p<0.05)$. Abbreviations: Ts.BMD-total skeleton bone mineral density; Ts.BMC-total skeleton bone mineral content; Ts.Ar-total skeleton area; t.BMD-tibia bone mineral density; t.BMC-tibia bone mineral content; t.Ar-tibia bone mineral area.

\section{4. pQCT Analysis of Tibia}

The usage of high-energy diet F significantly increased the values of Ct.BMC and Ct.vBMD of the tibia in offspring females ( $9 \%$ and $7 \%$, respectively) and males ( $12 \%$ and $7 \%$, respectively). Tibia diaphysis of offspring in group $\mathrm{F}$ was also characterized by a significantly greater thickness of cortical bone tissue (Ct.Th) by $4 \%$ and by $9 \%$, respectively. The values of the other parameters (Ct.Ar, Peri.C and Endo.C) of the tibia were similar between the sexes in groups $\mathrm{S}$ and $\mathrm{F}$ (Table 3 ). 
Table 3. The tomographic (pQCT) parameters of the total cross-section of the diaphysis and the proximal metaphysis as well as cortical and trabecular bone tissue of the tibia of female and male rats on the weaning day.

\begin{tabular}{|c|c|c|c|c|c|c|}
\hline \multirow{2}{*}{ Item } & \multicolumn{3}{|c|}{ Female } & \multicolumn{3}{|c|}{ Male } \\
\hline & $S$ & $F$ & $p$-Value & $S$ & $F$ & $p$-Value \\
\hline \multicolumn{7}{|c|}{ pQCT analysis of tibia diaphysis ( $50 \%$ of bone length) } \\
\hline $\begin{array}{l}\text { Tot.BMC } \\
(\mathrm{mg} / \mathrm{mm})\end{array}$ & $0.86 \pm 0.05$ & $0.92 \pm 0.06$ & 0.523 & $0.86 \pm 0.04$ & $0.98 \pm 0.03$ & 0.053 \\
\hline $\begin{array}{l}\text { Tot.vBMD } \\
\left(\mathrm{mg} / \mathrm{mm}^{3}\right)\end{array}$ & $406 \pm 13$ & $422 \pm 20$ & 0.719 & $396 \pm 18$ & $423 \pm 14$ & 0.260 \\
\hline $\begin{array}{l}\text { Tot.Ar } \\
\left(\mathrm{mm}^{2}\right)\end{array}$ & $2.15 \pm 0.03$ & $2.19 \pm 0.08$ & 0.734 & $2.20 \pm 0.10$ & $2.32 \pm 0.08$ & 0.378 \\
\hline $\begin{array}{l}\text { Peri.C } \\
(\mathrm{mm})\end{array}$ & $5.2 \pm 0.1$ & $5.2 \pm 0.1$ & 0.749 & $5.3 \pm 0.1$ & $5.4 \pm 0.1$ & 0.366 \\
\hline $\begin{array}{l}\text { Endo.C } \\
(\mathrm{mm})\end{array}$ & $3.8 \pm 0.1$ & $3.7 \pm 0.1$ & 0.890 & $3.8 \pm 0.1$ & $3.9 \pm 0.1$ & 0.444 \\
\hline $\begin{array}{c}\text { Ct.BMC } \\
(\mathrm{mg} / \mathrm{mm})\end{array}$ & $0.85 \pm 0.03$ & $0.93 \pm 0.04$ & $0.032 *$ & $0.86 \pm 0.02$ & $0.96 \pm 0.02$ & $0.006^{*}$ \\
\hline $\begin{array}{l}(\mathrm{Ct} . v B M D \\
\left(\mathrm{mg} / \mathrm{mm}^{3}\right)\end{array}$ & $786 \pm 7$ & $841 \pm 9$ & $0.032 *$ & $814 \pm 6$ & $871 \pm 9$ & $0.016^{*}$ \\
\hline $\begin{array}{l}\text { Ct.Ar } \\
(\mathrm{mm} 2)\end{array}$ & $1.02 \pm 0.02$ & $1.08 \pm 0.03$ & 0.133 & $1.06 \pm 0.03$ & $1.11 \pm 0.02$ & 0.250 \\
\hline $\begin{array}{l}\text { Ct.Th } \\
(\mathrm{mm})\end{array}$ & $0.229 \pm 0.002$ & $0.242 \pm 0.004$ & $0.036 *$ & $0.234 \pm 0.002$ & $0.254 \pm 0.003$ & 0.001 * \\
\hline \multicolumn{7}{|c|}{ pQCT analysis of tibia proximal metaphysis } \\
\hline $\begin{array}{l}\text { Tot.BMC } \\
(\mathrm{mg} / \mathrm{mm})\end{array}$ & $1.6 \pm 0.1$ & $1.9 \pm 0.1$ & $0.017^{*}$ & $1.7 \pm 0.1$ & $2.1 \pm 0.1$ & $0.006 *$ \\
\hline $\begin{array}{l}\text { Tot.vBMD } \\
\left(\mathrm{mg} / \mathrm{mm}^{3}\right)\end{array}$ & $271 \pm 8$ & $322 \pm 14$ & $0.007^{*}$ & $254 \pm 9$ & $322 \pm 11$ & $0.0003 *$ \\
\hline $\begin{array}{l}\text { Tot.Ar } \\
\left(\mathrm{mm}^{2}\right)\end{array}$ & $6.0 \pm 0.2$ & $6.0 \pm 0.3$ & 0.892 & $6.6 \pm 0.4$ & $6.5 \pm 0.3$ & 0.789 \\
\hline $\begin{array}{c}\text { Tb.BMC } \\
(\mathrm{mg} / \mathrm{mm})\end{array}$ & $0.28 \pm 0.02$ & $0.40 \pm 0.03$ & $0.005^{*}$ & $0.29 \pm 0.03$ & $0.42 \pm 0.03$ & $0.012 *$ \\
\hline $\begin{array}{l}(\mathrm{Tb} . v B M D \\
\left(\mathrm{mg} / \mathrm{mm}^{3}\right)\end{array}$ & $92 \pm 12$ & $143 \pm 14$ & 0.018 * & $80 \pm 16$ & $140 \pm 14$ & $0.015^{*}$ \\
\hline $\begin{array}{l}\mathrm{Tb} . \mathrm{Ar} \\
(\mathrm{mm} 2)\end{array}$ & $2.7 \pm 0.1$ & $2.7 \pm 0.2$ & 0.848 & $3.0 \pm 0.2$ & $2.9 \pm 0.1$ & 0.820 \\
\hline
\end{tabular}

Results are the means \pm S.E.M. $(n=8)$. Statistically significant differences between $S$ and F groups were established by the $t$-Student $(P<0.05)$ and marked by *. Abbreviations for cortical bone tissue-Tot.BMC-Total slice bone mineral content, Tot.vBMD-total slice volumetric bone mineral density, Tot.Ar-total slice bone area, Ct.Ar-cortical bone area, Ct.BMC cortical bone mineral content, Ct.vBMD-cortical volumetric bone mineral density, Ct.Th-cortical thickness, Peri.C periosteal circumference, Endo.C endosteal circumference. Abbreviations for trabecular bone tissue-Tot.BMC-total slice bone mineral content, Tot.vBMD-total slice volumetric bone mineral density, Tot.Ar-total slice bone area, $\mathrm{Tb}$.Ar-trabecular bone area, Tb.BMC-trabecular bone mineral content and Tb.vBMD-trabecular volumetric bone mineral density.

Statistically significant increase of the value of volumetric mineral density (Tb.vBMD) ( $55 \%$ and $75 \%$, respectively) and the content of trabecular bone mineral tissue (Tb.BMC) ( $43 \%$ and $45 \%$, respectively) were noted in both females and males from group $\mathrm{F}$. The trabecular bone area (Tb.Ar) of the proximal part of the tibia in groups $S$ and $F$ remained at a similar level (Table 3).

\section{5. $\mu \mathrm{CT}$ Analysis of Trabecular Bone Tissue in the Proximal Metaphysis}

Micro CT measurements showed a significant increase in bone volume fraction $(\mathrm{BV} / \mathrm{TV})$ in females $(25 \%)$ and males $(37 \%)$ of group $\mathrm{F}$, while in the $\mathrm{S}$ groups, object 
surface density (BS/TV) significantly decreased (11\% in both sexes). The dietary-induced obesity of parents significantly decreased the Tb.N (20\% and 17\%, respectively), decreased the Tb.Sp (24\% and 29\%, respectively) and increased Tb.Th (43\% and $45 \%$, respectively) measurements in female and male offspring. Moreover, the structure model index (SMI) decreased in offspring from the F group by $76 \%$ in females and by $88 \%$ in males (Table 4 ).

Table 4. Micro-CT measurement of the trabecular bone tissue in the proximal tibia metaphysis of female and male rats on the weaning day.

\begin{tabular}{|c|c|c|c|c|c|c|}
\hline \multirow{2}{*}{ Item } & \multicolumn{3}{|c|}{ Female } & \multicolumn{3}{|c|}{ Male } \\
\hline & $S$ & $F$ & $p$-Value & $S$ & $F$ & $p$-Value \\
\hline $\begin{array}{c}\mathrm{TV} \\
\left(\mathrm{mm}^{3}\right)\end{array}$ & $14.8 \pm 0.8$ & $15.5 \pm 0.1$ & 0.35 & $15.0 \pm 0.5$ & $15.6 \pm 0.4$ & 0.43 \\
\hline $\begin{array}{c}\mathrm{BV} \\
\left(\mathrm{mm}^{3}\right)\end{array}$ & $8.8 \pm 0.3$ & $11.6 \pm 0.1$ & $<0.0001^{*}$ & $8.1 \pm 0.2$ & $12.3 \pm 0.3$ & $<0.0001$ * \\
\hline $\begin{array}{c}\mathrm{BS} \\
\left(\mathrm{mm}^{2}\right)\end{array}$ & $372 \pm 16$ & $351 \pm 6$ & 0.280 * & $398 \pm 9$ & $369 \pm 5$ & $0.015^{*}$ \\
\hline $\begin{array}{c}\text { BS/TV } \\
(1 / \mathrm{mm})\end{array}$ & $25.3 \pm 0.6$ & $22.6 \pm 0.4$ & 0.004 * & $26.6 \pm 0.5$ & $23.7 \pm 0.3$ & $0.0006^{*}$ \\
\hline $\begin{array}{c}\mathrm{BV} / \mathrm{TV} \\
(\%)\end{array}$ & $59.2 \pm 1.6$ & $74.2 \pm 0.9$ & $<0.0001^{*}$ & $58.1 \pm 0.9$ & $79.5 \pm 2.6$ & $<0.0001$ * \\
\hline $\begin{array}{l}\text { Tb.Th } \\
(\mathrm{mm})\end{array}$ & $0.21 \pm 0.02$ & $0.30 \pm 0.02$ & 0.005 * & $0.22 \pm 0.01$ & $0.32 \pm 0.01$ & $<0.0007^{*}$ \\
\hline $\begin{array}{c}\text { Tb.N } \\
(1 / \mathrm{mm})\end{array}$ & $3.0 \pm 0.1$ & $2.4 \pm 0.1$ & $0.003 *$ & $2.9 \pm 0.1$ & $2.4 \pm 0.1$ & $0.0007^{*}$ \\
\hline $\begin{array}{l}\text { Tb.Sp } \\
(\mathrm{mm})\end{array}$ & $0.17 \pm 0.01$ & $0.13 \pm 0.01$ & $0.006^{*}$ & $0.17 \pm 0.01$ & $0.12 \pm 0.01$ & $0.014^{*}$ \\
\hline SMI & $-1.7 \pm 0.1$ & $-3.0 \pm 0.1$ & $<0.0001 *$ & $-1.6 \pm 0.1$ & $-3.0 \pm 0.1$ & $<0.0001$ * \\
\hline
\end{tabular}

Results are the means \pm S.E.M. $(n=8)$. Statistically significant differences between $\mathrm{S}$ and $\mathrm{F}$ groups were established by the $t$-Student $(p<0.05)$ and marked by *. Abbreviations: TV-total volume, BV-bone volume, BS-bone surface, BS/TV-object surface density, BV/TV-bone volume density, Tb.Th-trabecular thickness, Tb.Sptrabecular separation, Tb.N-trabecular number, SMI-structure model index.

\subsection{Mechanical Analysis of Tibia}

Tomographic examination showed that the strain/strength index (xSSI) of the tibia of the offspring of rats from group $\mathrm{F}$ was significantly higher by $14 \%$ in females and by $11 \%$ in males. The evaluation of the mechanical properties by the three-point test of the tibia from females and males of group $\mathrm{F}$ also showed a significant increase in maximum strength (Fmax) (63\% and 89\%, respectively). Besides, females and males of group $\mathrm{F}$ revealed Young's modulus of elasticity (Emod) of $60 \%$ and $60 \%$, respectively, and the work to ultimate strength (W/Fmax) of 20\% and 53\%, respectively (Figure 2). 

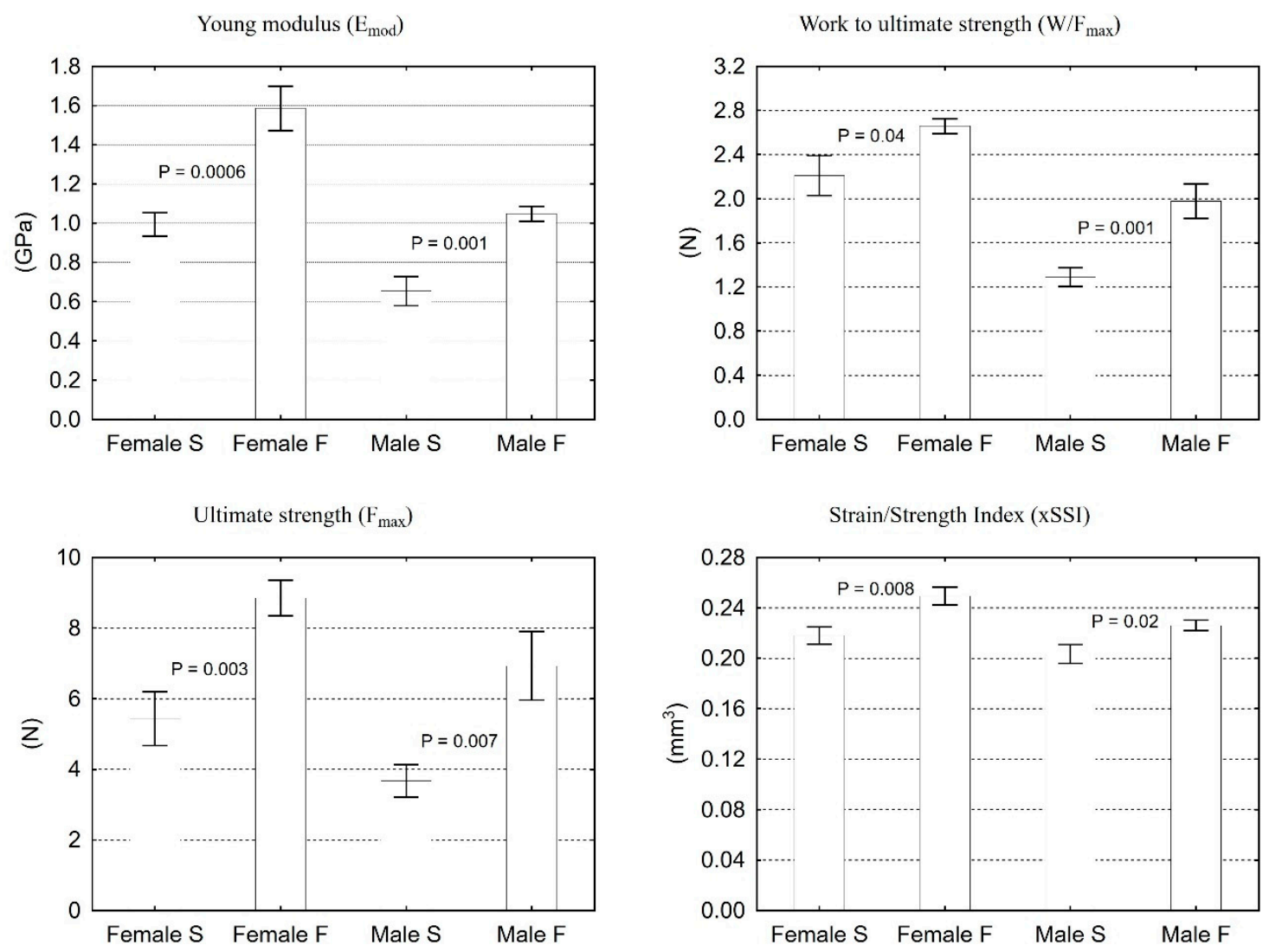

Figure 2. Mechanical parameters of isolated tibia established using three-point bending test and pQCT of female and male rats on the weaning day. Results are the means \pm S.E.M. $(n=8)$. Statistically significant differences between $S$ and $F$ groups were established by the $t$-Student $(p<0.05)$.

\subsection{Biochemistry}

Osteocalcin concentration significantly increased in the blood serum of females $(7 \%)$ and males ( $8 \%$ ) from group F, while the CTX-I significantly decreased in both sexes $(14 \%$ and $18 \%$, respectively). The activity of the ALP in offspring from the parents fed the high-energy diet significantly increased in both sexes. The level of 25(OH)D3 concentration in blood serum of females offspring from group $\mathrm{F}(6 \%)$ tended to lower values as compared to the $S$ group, while in males $(7 \%)$, a significant increase of the $25(\mathrm{OH}) \mathrm{D} 3$ concentration in the F group was noted. No significant changes were evidenced in the concentration of ionized $\mathrm{Ca}$ and $\mathrm{P}$ (Table 5). 
Table 5. Biochemical markers of bone metabolism and concentration of ionized calcium and phosphorus in blood serum of female and male rats on the weaning day.

\begin{tabular}{|c|c|c|c|c|c|c|}
\hline \multirow{2}{*}{ Item } & \multicolumn{3}{|c|}{ Female } & \multicolumn{3}{|c|}{ Male } \\
\hline & $S$ & $F$ & $p$-Value & $S$ & $F$ & $p$-Value \\
\hline $\begin{array}{l}\text { Osteocalcin } \\
(\mathrm{ng} / \mathrm{mL})\end{array}$ & $10.5 \pm 0.1$ & $11.2 \pm 0.1$ & $0.001 *$ & $10.1 \pm 0.2$ & $10.9 \pm 0.1$ & 0.005 * \\
\hline $\begin{array}{l}\mathrm{bALP} \\
\mathrm{U} / \mathrm{L}\end{array}$ & $517 \pm 43$ & $803 \pm 59$ & $0.002 *$ & $539 \pm 27$ & $670 \pm 53$ & $0.002 *$ \\
\hline $\begin{array}{c}\text { CTX-I } \\
(\mathrm{ng} / \mathrm{mL})\end{array}$ & $30.9 \pm 1.2$ & $26.6 \pm 0.4$ & $0.003 *$ & $28.0 \pm 0.5$ & $23.0 \pm 0.9$ & $<0.0001 *$ \\
\hline $\begin{array}{c}25 \mathrm{OH} \text { D3 } \\
(\mathrm{ng} / \mathrm{mL})\end{array}$ & $49.0 \pm 2.6$ & $45.9 \pm 2.9$ & 0.424 & $44.3 \pm 1.8$ & $47.5 \pm 1.9$ & $0.042 *$ \\
\hline $\begin{array}{l}\text { Phosphorus } \\
\text { (mmol/L) }\end{array}$ & $11.7 \pm 0.3$ & $12.6 \pm 0.8$ & 0.363 & $12.6 \pm 0.6$ & $12.2 \pm 0.5$ & 0.329 \\
\hline $\begin{array}{l}\text { Calcium } \\
(\mathrm{mmol} / \mathrm{L})\end{array}$ & $11.5 \pm 0.1$ & $11.6 \pm 0.2$ & 0.750 & $11.8 \pm 0.3$ & $11.5 \pm 0.1$ & 0.942 \\
\hline
\end{tabular}

Results are the means \pm S.E.M. $(n=8)$. Statistically significant differences between $S$ and $F$ groups were established by the $t$-Student $(p<0.05)$ and marked by ${ }^{*}$. Abbreviations: bALP-bone-specific alkaline phosphatase, CTX-I-C-terminal telopeptides of type I collagen.

\section{Discussion}

Our research was conducted to determine the programming influence of persistent parental obesity on the mineralization, structure and mechanical strength of bone tissue of rat offspring on the day of weaning. Offspring of both sexes came from parents with fixed dietary-induced obesity by high-energy diet (F) and from parents fed the standard diet (S). We used a tibia as a model bone.

DXA is now the gold standard in the study of the skeletal system of humans and animals. The test is readily available, the results are highly comparable and the patients are exposed to a low dose of radiation. An additional benefit of the DXA is the ability to evaluate the Body Composition through fat mass (FM), lean mass (LM) and soft tissue (ST) analysis. Using this method in our research, we showed that the main reason for the higher body weight of F offspring was the FM increase. Sectional measurements of the masses of the particular depots of the adipose tissue showed that the greatest weight gain in females and males was related to the visceral adipose tissue.

Similar observations have been published by other authors [22-24]. Additionally, both sexes of F offspring had greater LM, as previously was reported by de Albuquerque Maia et al. [24]. Moreover, Madeira et al. [25] documented a positive correlation between LM and $\mathrm{BMD}$, as well as bone microstructure in obese adults with metabolic syndrome, suggesting a relationship between LM and bone health. In line with the assumptions of these authors and regarding the significant increase of LM in F offspring, we considered the impact of LM on bone density. In contemporary literature, the two views of the influence of overweight and obesity on the metabolism of bone tissue clash [7]. It seems that the dominant view is that the adipose tissue harms the skeletal system, increasing bone susceptibility to fracture $[5,10,26]$.

However, studies documenting the beneficial effect of weight gain on the metabolism of the skeletal system that result in an increase of BMD and bone mechanical strength cannot be omitted $[9,27]$. The mentioned DXA analysis allows for a planar evaluation of bone tissue. During the test, we obtain two main values, i.e., BMC, which is the effect of calcium absorption and its deposition in the bone [28], and bone area, mainly determined by the synthesis of proteins responsible for bone structure [19]. The proportion of BMC to bone area allows for estimation of BMD expressed in $\mathrm{g} / \mathrm{cm} 2$ given by DXA. In the presented research, both t.BMC and t.Ar showed a significant increase in values. Still, only t.BMD tended to be higher. It should be assumed that the lack of significant changes 
of t.BMD may result from a similar proportion of the increase of t.BMC and t.Ar values of the female and male tibia in groups $S$ and $F$, which means that despite the increased Ca retention in bones and the effective synthesis of bone matrix proteins increasing the bone surface, t.BMD does not change significantly. Interestingly, a similar relationship was observed by de Albuquerque Maia et al. [24].

DXA, despite its advantages, does not allow for the spatial assessment of bone tissue and provides a $2 \mathrm{D}$ areal rather than a volumetric calculation of bone size and mass. A three-dimensional analysis is possible using the pQCT and the $\mu \mathrm{CT}$. The pQCT allows for a separate evaluation of the cortical and the trabecular bone tissue in a volumetric approach in any chosen bone location (Figure 3).

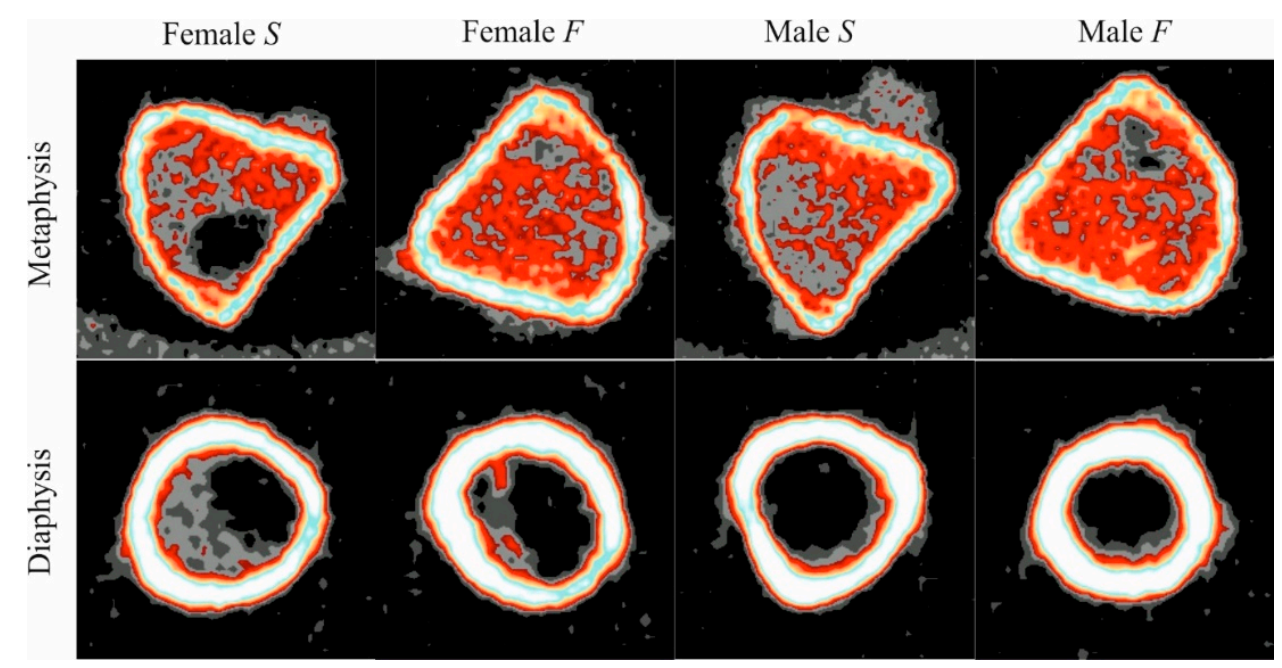

Figure 3. Representative peripheral quantitative computed tomography (pQCT) scan images of tibia performed in the proximal metaphysis and midshaft of the diaphysis of female and male rats on the weaning day.

In our research, the evaluation of the cortical bone tissue was carried out in the center of the mid-shaft and significantly higher values of the Ct.vBMD and the Ct.BMC in the female and male offspring of group F were discovered. The results of our research are consistent with previous studies [24]. It is worth noting that the high-energy diet applied to parents had a significant impact on the geometric properties of the tibia of both sexes of offspring, as indicated by the increased thickness of the cortical bone tissue (Ct.Th).

The trabecular bone tissue was also assessed by tomography. It must be underlined that trabecular bone tissue is more sensitive to any treatment, and metabolic processes affecting mineralization or bone structure are more intensive. The analysis in the proximal diaphysis also showed higher values of Tb.vBMD and Tb.BMC in group F female and male offspring. However, the data obtained during the pQCT measurements did not explain the grounds of these changes. This is possible only when the microarchitecture of the trabecular compartment is studied using $\mu \mathrm{CT}$.

This showed that after applying a high-energy diet in parents, the bone trabeculae analyzed in the proximal part of the tibia from the F offspring were characterized by a greater thickness (Tb.Th) and a smaller separation between them (Tb.Sp), despite the reduction in their number (Tb.N). Changes in Tb.Th and Tb.Sp in combination with an increase of bone volume fraction (BV/TV), and decrease of bone surface density (BS/TV), as well as structure model index (SMI) indicate that the trabecular compartment is denser in the proximal tibia of females and males from group F [29]. As previously mentioned, numerous studies demonstrated that the increased depot of adipose tissue has a destructive effect on bones, leading to a decrease in their mechanical strength and an increased susceptibility to fracture. This thesis was proven by the observations of obese children at increased risk of fractures [30], who have reported more frequent bone fractures [31,32] and repeated fractures [33]. 
It is believed that increased bone fragility in obese children may result from a limited dietary intake of vitamin D and calcium, as well as a tendency to a sedentary lifestyle [3436]. On the other hand, cross-sectional and longitudinal studies indicate that the relationship between the mass of the adipose tissue and the quality of bone tissue may differ at different stages of growth and development of the organism. It has been suggested that in the early stages of life, the increase in FM and LM has a beneficial effect on bone tissue [37], and the moment of change of the nature of the impact may depend on the exceeding of the hypothetical "fat threshold" at which an overabundance of fat tissue imparts a deleterious effect on the growing skeleton $[38,39]$.

This is also confirmed by our study, in which the analysis of mechanical resistance was carried out using pQCT and the three-point bending test. The pQCT test allows for the in vivo analysis of bone tissue, and the obtained Strength-Strain Index (xSSI) shows a high correlation with the strength parameters obtained during loading tests [40]. The bone analysis carried out in our studies on the day of weaning, with the use of pQCT and three-point bending test, confirms the above thesis, as it was demonstrated that the mechanical strength of the tibia shaft of offspring rats from group $\mathrm{F}$ was significantly higher.

The concentration of the CTX-I reflects the intensity of osteoclastic bone tissue resorption. The osteocalcin level, as a bone-specific protein secreted by osteoblast, reflects the metabolic activity of osteoblasts. The activity of the bone-specific alkaline phosphatase (bALP) [41] has a similar diagnostic value. In our research, the abovementioned biochemical markers of bone metabolism confirm that in the female and male offspring of group $F$, increased body weight has a beneficial effect on the development and mineralization of the bone tissue.

Vitamin D is well known to play a key role in bone metabolism and calcium homeostasis. It is clear that in adults there is a close correlation between vitamin D level and obesity. Herein, it appears that obesity is associated with a reduction of the $25(\mathrm{OH}) \mathrm{D} 3$ concentration [42]. In our study, we found that the level of the $25(\mathrm{OH}) \mathrm{D} 3$ is sexually different. The offspring of $\mathrm{F}$ females tended to the lower 25(OH)D3 levels, which is consistent with the observations of de Albuquerque Maia [24]. In the male offspring from group F, a 7\% increase of the 25(OH)D3 concentration was found. These data confirm the earlier study performed by de Albuquerque Maia et al. [43] carried out on weaned rats. However, the authors did not provide information about the sex of the rats used in the experiment. At this moment, it is difficult to explain the essence of the sexual difference of the $25(\mathrm{OH}) \mathrm{D} 3$ concentration, and this problem requires further research.

However, our research has some important limitations. In line with the assumptions, the starting point of our experiment was the simultaneous induction of maternal and paternal obesity. The obtained results reflect the programming influence of obesity of both parents on the skeletal system of their offspring. In the literature, the most frequently described relationships on organogenesis and metabolism of the offspring are that of maternal obesity or of significant changes in nutrition in the period preceding or during pregnancy [44]. Studies of the impact of father obesity on offspring programming effects are not numerous, but they confirm the existence of such a relationship. McPherson et al. [45] suggest that paternal overweight/obesity induces paternal programming of offspring phenotypes likely mediated through genetic and epigenetic changes in spermatozoa. Human and animal studies have shown that paternal obesity increases the risk of diabetes type II and cardiovascular diseases [46]. Therefore, it is important and necessary to extend the research to assess the exclusive impact of fixed paternal obesity on the programming of skeletal changes in offspring.

\section{Conclusions}

It should be emphasized that fixed parental obesity exerts a programming influence on the growth, development and mineralization of the skeletal system of the offspring. Moreover, it significantly intensifies mineralization, and as a consequence, increases bone 
strength. Our research is in agreement with the assumptions but was limited to a specific age group, i.e., weaning day. However, taking into account numerous reports characterizing the effect of adipose tissue on bone tissue, further work is undoubtedly necessary to determine the time intervals determining the metabolic relationship between adipose tissue and bone in subsequent stages of life. Such studies will allow an understanding of the conditions for determining the "fat threshold", upon which the process of exceeding the destructive effect of adipose tissue on bone metabolism is initiated.

Author Contributions: Conceptualization, R.P.R. and M.B.; methodology, R.P.R., M.B., M.O. and P.P.; validation, R.P.R., M.B., M.O. and P.P.; formal analysis, D.W. and J.W.; investigation, M.M. and A.K.; data curation, D.W., J.W., M.M. and A.K.; resources, R.P.R., M.B., M.O.; writing-original draft preparation, R.P.R.; writing-review and editing, M.B., M.O.; visualization, P.P. and D.W.; supervision, R.P.R. and M.B.; project administration, J.W. All authors have read and agreed to the published version of the manuscript.

Funding: This research received no external funding.

Institutional Review Board Statement: The study was conducted according to the guidelines of the Declaration of Helsinki, and approved by the 2nd Local Ethics Committee in Lublin (Resolution nr 32/2015, 26 May 2015).

Data Availability Statement: The data presented in this study are available on request from the corresponding author.

Acknowledgments: The authors would like to thank Jolanta Stec, Wioletta Gizka and Ireneusz Banasiewicz for the help shown in the implementation of this work.

Conflicts of Interest: The authors declare no conflict of interest.

\section{References}

1. De Moura, E.G.; Lisboa, P.C.; Passos, M.C. Neonatal programming of neuroimmunomodulation-Role of adipocytokines and neuropeptides. Neuroimmunomodulation 2008, 15, 176-188. [CrossRef]

2. De Moura, E.G.; Passos, M.C. Neonatal programming of body weight regulation and energetic metabolism. Biosci. Rep. 2005, 25, 251-269. [CrossRef] [PubMed]

3. Lee, E.Y.; Yoon, K.H. Epidemic obesity in children and adolescents: Risk factors and prevention. Front. Med. 2018, 12, 658-666. [CrossRef] [PubMed]

4. Mohan, R.; Baumann, D.; Alejandro, E.U. Fetal undernutrition, placental insufficiency, and pancreatic beta-cell development programming in utero. Am. J. Physiol. Regul. Integr. Comp. Physiol. 2018, 315, R867-R878. [CrossRef]

5. Devlin, M.J.; Bouxsein, M.L. Influence of pre- and peri-natal nutrition on skeletal acquisition and maintenance. Bone 2012, 50, 444-451. [CrossRef] [PubMed]

6. McGown, C.; Birerdinc, A.; Younossi, Z.M. Adipose tissue as an endocrine organ. Clin. Liver Dis. 2014, 18, 41-58. [CrossRef]

7. Bienko, M.; Lis, A.; Wolski, D.; Radzki, R.P. Relationships between bone tissue and fat tissue. Med. Weter. 2016, 72, 217-224.

8. Calabro, P.; Yeh, E.T. Obesity, inflammation, and vascular disease: The role of the adipose tissue as an endocrine organ. Subcell Biochem. 2007, 42, 63-91. [PubMed]

9. De Laet, C.; Kanis, J.A.; Oden, A.; Johanson, H.; Johnell, O.; Delmas, P.; Eisman, J.A.; Kroger, H.; Fujiwara, S.; Garnero, P.; et al. Body mass index as a predictor of fracture risk: A meta-analysis. Osteoporos Int. 2005, 16, 1330-1338. [CrossRef]

10. Hwang, D.K.; Choi, H.J. The relationship between low bone mass and metabolic syndrome in Korean women. Osteoporos Int. 2010, 21, 425-431. [CrossRef]

11. Sakata, T.; Halloran, B.P.; Elalieh, H.Z.; Munson, S.J.; Rudner, L.; Venton, L.; Ginzinger, D.; Rosen, C.J.; Bikle, D.D. Skeletal unloading induces resistance to insulin-like growth factor I on bone formation. Bone 2003, 32, 669-680. [CrossRef]

12. Blum, M.; Harris, S.S.; Must, A.; Naumova, E.N.; Phillips, S.M.; Rand, W.M.; Dawson-Hughes, B. Leptin, body composition and bone mineral density in premenopausal women. Calcif. Tissue Int. 2003, 73, 27-32. [CrossRef]

13. Hsu, Y.H.; Venners, S.A.; Terwedow, H.A.; Feng, Y.; Niu, T.; Li, Z.; Laird, N.; Brain, J.D.; Cummings, S.R.; Bouxsein, M.L.; et al. Relation of body composition, fat mass, and serum lipids to osteoporotic fractures and bone mineral density in Chinese men and women. Am. J. Clin. Nutr. 2006, 83, 146-154. [CrossRef]

14. Dobrowolski, P.; Tomaszewska, E.; Bienko, M.; Radzki, R.P.; Pierzynowski, S.G. The effect of dietary administration of 2oxoglutaric acid on the cartilage and bone of growing rats. Br. J. Nutr. 2013, 110, 651-658. [CrossRef] [PubMed]

15. Eastell, R.; Lambert, H. Diet and healthy bones. Calcif. Tissue Int. 2002, 70, 400-404. [CrossRef]

16. Topolska, K.; Radzki, R.P.; Filipiak-Florkiewicz, A.; Florkiewicz, A.; Leszczynska, T.; Cieslik, E. Fructan-Enriched Diet Increases Bone Quality in Female Growing Rats at Calcium Deficiency. Plant Foods Hum. Nutr. 2018, 73, 172-179. [CrossRef] [PubMed] 
17. Howie, G.J.; Sloboda, D.M.; Kamal, T.; Vickers, M.H. Maternal nutritional history predicts obesity in adult offspring independent of postnatal diet. J. Physiol. 2009, 587, 905-915. [CrossRef]

18. Longhi, R.; Almeida, R.F.; Machado, L.; Duarte, M.; Souza, D.G.; Machado, P.; de Assis, A.M.; Quincozes-Santos, A.; Souza, D.O. Effect of a trans fatty acid-enriched diet on biochemical and inflammatory parameters in Wistar rats. Eur. J. Nutr. 2017, 56, 1003-1016. [CrossRef]

19. Lac, G.; Cavalie, H.; Ebal, E.; Michaux, O. Effects of a high fat diet on bone of growing rats. Correlations between visceral fat, adiponectin and bone mass density. Lipids Health Dis. 2008, 7, 16. [CrossRef] [PubMed]

20. Koolhaas, J.M. The laboratory rat. In The UFAW Handbook on the Care and Management of Laboratory and Other Research Animals, 8th ed.; Hubrecht, R., Kirkwood, J., Eds.; The Universities Federation for Animal Welfare: Hertfordshire, UK, 2010 ; pp. $311-326$.

21. Radzki, R.P.; Bienko, M.; Polak, P.; Szkucik, K.; Ziomek, M.; Ostapiuk, M.; Bienias, J. Is the consumption of snail meat actually healthy? An analysis of the osteotropic influence of snail meat as a sole source of protein in growing rats. J. Anim. Physiol. Anim. Nutr. 2018, 102, e885-e891. [CrossRef]

22. Rodrigues, A.L.; de Moura, E.G.; Passos, M.C.; Dutra, S.C.; Lisboa, P.C. Postnatal early overnutrition changes the leptin signalling pathway in the hypothalamic-pituitary-thyroid axis of young and adult rats. J. Physiol. 2009, 587, 2647-2661. [CrossRef] [PubMed]

23. Conceicao, E.P.; Franco, J.G.; Oliveira, E.; Resende, A.C.; Amaral, T.A.; Peixoto-Silva, N.; Passos, M.C.; Moura, E.G.; Lisboa, P.C. Oxidative stress programming in a rat model of postnatal early overnutrition-Role of insulin resistance. J. Nutr. Biochem. 2013, 24, 81-87. [CrossRef] [PubMed]

24. De Albuquerque Maia, L.; Lisboa, P.C.; de Oliveira, E.; da Conceicao, E.P.; Lima, I.C.; Lopes, R.T.; Ruffoni, L.D.; Nonaka, K.O.; de Moura, E.G. Bone structure and strength are enhanced in rats programmed by early overfeeding. Horm. Metab. Res. 2014, 46, 259-268. [CrossRef] [PubMed]

25. Madeira, E.; Mafort, T.T.; Madeira, M.; Guedes, E.P.; Moreira, R.O.; de Mendonca, L.M.; Lima, I.C.; de Pinho, P.R.; Lopes, A.J.; Farias, M.L. Lean mass as a predictor of bone density and microarchitecture in adult obese individuals with metabolic syndrome. Bone 2014, 59, 89-92. [CrossRef] [PubMed]

26. Dimitri, P. Fat and bone in children-Where are we now? Ann. Pediatr. Endocrinol. Metab. 2018, 23, 62-69. [CrossRef]

27. El Hage, R.; Bachour, F.; Sebaaly, A.; Issa, M.; Zakhem, E.; Maalouf, G. The influence of weight status on radial bone mineral density in Lebanese women. Calcif. Tissue Int. 2014, 94, 465-467. [CrossRef]

28. Møgaard, C.; Hoppe, C.; Michaelsen, K.F. Bone mineral content (BMC) at 10 years of age is related to growth in infancy. Pediatric Res. 1999, 45, 915. [CrossRef]

29. Kang, S.R.; Bok, S.C.; Choi, S.C.; Lee, S.S.; Heo, M.S.; Huh, K.H.; Kim, T.I.; Yi, W.J. The relationship between dental implant stability and trabecular bone structure using cone-beam computed tomography. J. Periodontal Implant Sci. 2016, 46, 116-127. [CrossRef]

30. Kim, S.J.; Ahn, J.; Kim, H.K.; Kim, J.H. Obese children experience more extremity fractures than nonobese children and are significantly more likely to die from traumatic injuries. Acta Paediatr. 2016, 105, 1152-1157. [CrossRef]

31. Goulding, A.; Grant, A.M.; Williams, S.M. Bone and body composition of children and adolescents with repeated forearm fractures. J. Bone Miner. Res. 2005, 20, 2090-2096. [CrossRef]

32. Manias, K.; McCabe, D.; Bishop, N. Fractures and recurrent fractures in children; varying effects of environmental factors as well as bone size and mass. Bone 2006, 39, 652-657. [CrossRef] [PubMed]

33. Jones, I.E.; Taylor, R.W.; Williams, S.M.; Manning, P.J.; Goulding, A. Four-year gain in bone mineral in girls with and without past forearm fractures: A DXA study. Dual energy X-ray absorptiometry. J. Bone Miner. Res. 2002, 17, 1065-1072. [CrossRef]

34. Wosje, K.S.; Khoury, P.R.; Claytor, R.P.; Copeland, K.A.; Hornung, R.W.; Daniels, S.R.; Kalkwarf, H.J. Dietary patterns associated with fat and bone mass in young children. Am. J. Clin. Nutr. 2010, 92, 294-303. [CrossRef] [PubMed]

35. Plesner, J.L.; Dahl, M.; Fonvig, C.E.; Nielsen, T.R.H.; Kloppenborg, J.T.; Pedersen, O.; Hansen, T.; Holm, J.C. Obesity is associated with vitamin D deficiency in Danish children and adolescents. J. Pediatr. Endocrinol. Metab. 2018, 31, 53-61. [CrossRef] [PubMed]

36. Black, R.E.; Williams, S.M.; Jones, I.E.; Goulding, A. Children who avoid drinking cow milk have low dietary calcium intakes and poor bone health. Am. J. Clin. Nutr. 2002, 76, 675-680. [CrossRef] [PubMed]

37. Sudhagoni, R.G.; Wey, H.E.; Djira, G.D.; Specker, B.L. Longitudinal effects of fat and lean mass on bone accrual in infants. Bone 2012, 50, 638-642. [CrossRef]

38. Burrows, M.; Baxter-Jones, A.; Mirwald, R.; Macdonald, H.; McKay, H. Bone mineral accrual across growth in a mixed-ethnic group of children: Are Asian children disadvantaged from an early age? Calcif. Tissue Int. 2009, 84, 366-378. [CrossRef]

39. Laddu, D.R.; Farr, J.N.; Laudermilk, M.J.; Lee, V.R.; Blew, R.M.; Stump, C.; Houtkooper, L.; Lohman, T.G.; Going, S.B. Longitudinal relationships between whole body and central adiposity on weight-bearing bone geometry, density, and bone strength: A pQCT study in young girls. Arch. Osteoporos. 2013, 8, 156. [CrossRef] [PubMed]

40. Ferretti, J.L.; Capozza, R.F.; Zanchetta, J.R. Mechanical validation of a tomographic (pQCT) index for noninvasive estimation of rat femur bending strength. Bone 1996, 18, 97-102. [CrossRef]

41. Gajewska, J.; Ambroszkiewicz, J.; Radomyska, B.; Chelchowska, M.; Oltarzewski, M.; Laskowska-Klita, T.; Milanowski, A. Serum markers of bone turnover in children and adolescents with classic galactosemia. Adv. Med. Sci. 2008, 53, 214-220. [CrossRef]

42. Bell, N.H.; Epstein, S.; Greene, A.; Shary, J.; Oexmann, M.J.; Shaw, S. Evidence for alteration of the vitamin D-endocrine system in obese subjects. J. Clin. Invest. 1985, 76, 370-373. [CrossRef] [PubMed] 
43. De Albuquerque Maia, L.; Lisboa, P.C.; de Oliveira, E.; da Silva Lima, N.; da Costa, C.A.; de Moura, E.G. Two models of early weaning decreases bone structure by different changes in hormonal regulation of bone metabolism in neonate rat. Horm. Metab. Res. 2013, 45, 332-337. [CrossRef] [PubMed]

44. Cirulli, F.; Musillo, C.; Berry, A. Maternal Obesity as a Risk Factor for Brain Development and Mental Health in the Offspring Neuroscience 2020, 447, 122-135. [CrossRef]

45. McPherson, N.O.; Fullston, T.; Aitken, R.J.; Lane, M. Paternal obesity, interventions, and mechanistic pathways to impaired health in offspring. Ann. Nutr. Metab. 2014, 64, 231-238. [CrossRef] [PubMed]

46. Eberle, C.; Kirchner, M.F.; Herden, R.; Stichling, S. Paternal metabolic and cardiovascular programming of their offspring: A systematic scoping review. PLoS ONE 2020, 15, e0244826. [CrossRef] [PubMed] 